\title{
Overview of current energy policy and standards in the building sector in Iran
}

\author{
M. Riazi ${ }^{1} \&$ S. M. Hosseyni ${ }^{2}$ \\ ${ }^{1}$ Energy Rating Services, UK \\ ${ }^{2}$ Islamic Azad University, Azadshahr Branch, Iran
}

\begin{abstract}
The enormous growth in urbanisation worldwide, particularly in developing countries, has negatively affected the local, regional and global environment. It will have a profound impact upon world demand for energy, if this trend continues. It should be noted that the major source of energy use in Iran is fossil fuel, which inevitably leads to exhaustion of energy supplies as well as environmental problems (notably air pollution and greenhouse gas emission). According to the energy balance 2008, the Iranian building sector accounts for about $42 \%$ of total energy use. This huge amount of energy consumption has pointed out the need for more restricted energy efficiency policies to address a substantial reduction of $\mathrm{CO}_{2}$ emission in the building sector and consequently ensuring climate security for future generations.

The authors made a careful consideration of the code for energy efficiency of buildings, the Iran national standard and the renewable energy status in the country. In this paper, relevant facts and figures about the Iranian building energy consumption and $\mathrm{CO}_{2}$ emission have been presented. The current energy efficiency policies have been reviewed, including: the national code for sustainable design- Code No. 19- and National standards related to energy efficiency. The government policies on development of environmentally friendly energy resources and their progress during the last decade have been presented. Code 19 and renewable energy policy have been implemented by 20 and 38 percent by 2010 respectively. Accordingly, it is essential to establish more efficient strategies in these cases to meet the government target. The paper
\end{abstract}


concludes by presenting possible solutions to overcome barriers in implementation of building energy regulation in Iran.

Keywords: energy policy, building sector, energy efficiency, renewable energy, Iran.

\section{Introduction}

Iran, with its young population, is the second largest country in the Middle East. The growing needs for housing and the lack of energy efficiency in existing buildings causes a considerable increase in the energy demand building sector. As the major source of energy use in Iran is fossil fuel, the chief environmental problem associated with energy consumption is greenhouse gas emission.

Building energy consumption accounts for $41.9 \%$ of the total energy use in Iran in 2008. The main sources of energy consumption are: natural gas $66 \%$, Petroleum 20\%, electricity $2.5 \%$ and other sources $1.5 \%$ [1].

Average energy consumption in the residential sector compared to the same conditions in Europe is over 2.5 times higher and in comparison with cold regions in Europe is over 3.5 times higher [2]. This shows the importance of this sector in energy efficiency policies.

In this paper, first, relevant facts and figures about the Iranian building energy consumption and their resources presented. Then the authors describe the general energy policy in Iran including; the national regulation and energy efficiency standards in the Iranian building sector. Finally, the government policies on development of renewable energy sources and their progress during the last decade reviewed. The paper concludes by discussing possible solutions to overcome barriers in implementation of energy efficiency policies in Iran.

\section{Analyses of the building energy consumption in Iran}

As mentioned before, building energy consumption accounts for $41.9 \%$ of the total energy use in Iran in 2008. Fig. 1 illustrates the building energy consumption in comparison to the total energy use in Iran from 2001 to 2008.

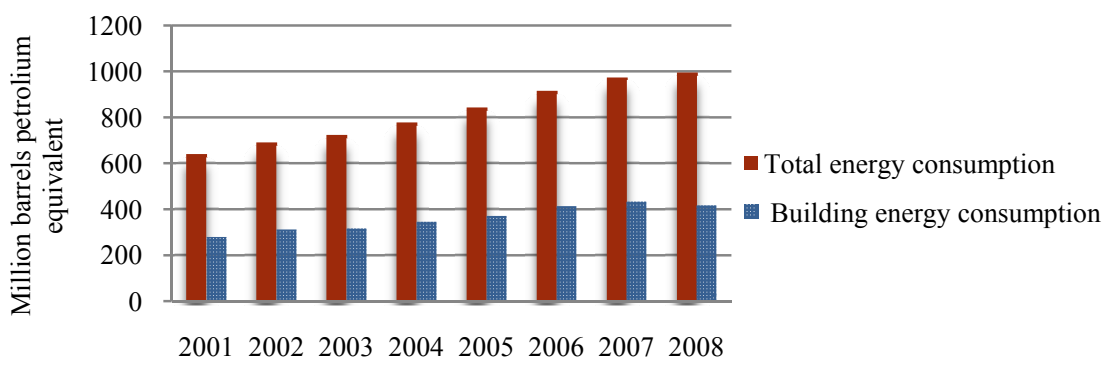

Figure 1: $\quad$ Building energy consumption in Iran [3]. 
Despite the growth in the energy consumption in the building sector during the last decade, there has been a slight decrease from $44.5 \%$ to $41.9 \%$ between 2007 and 2008, fig. 2. This achievement shows the positive impact of some policies, such as a price reform for energy, compiling Code No.19 (the national code for sustainable design) and incentive programmes.

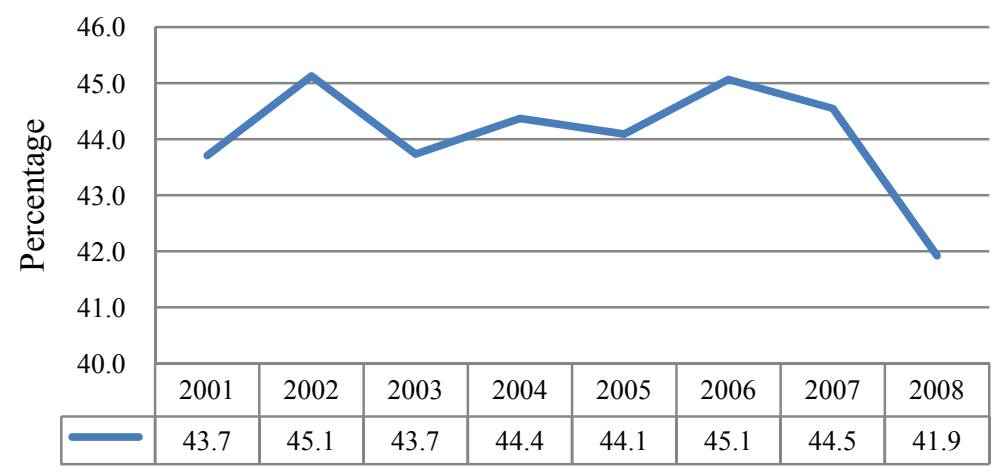

Figure 2: $\quad$ The percentage of building energy consumption in Iran [3].

As part of the building energy resources, natural gas and petroleum products account for $66 \%$ and $20 \%$ respectively, electricity $13 \%$ and renewable energies just $1 \%$. Figure 3 illustrates the proportion of share of fossil fuel resources, including natural gas and oil products, comprising the largest share of energy resources in the building sector. Considering the negligible share of renewable energy among energy sources a stricter response is obvious.



Figure 3: $\quad$ Share of energy resources in building sector in Iran [3].

Figure 4 shows the share of different energy consumers in buildings in Iran. Heating, cooling and hot water account for $83 \%$ of the overall usage, appliances 
for $8 \%$, lighting and other elements for $9 \%$. As heating, cooling and hot water are the main energy consumers in buildings, energy efficiency programmes in this area will have a profound impact on the energy consumption in the building sector.

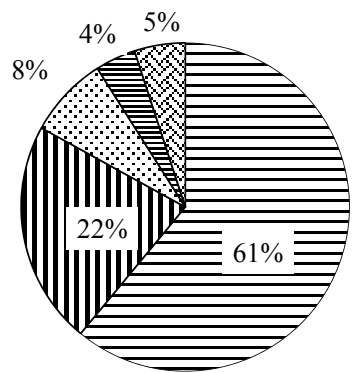

-Heating and cooling

口Hot water

$\square$ Appliance

目Lighting

चOther

Figure 4: $\quad$ Share of energy consumers in building sector in Iran [4].

The significant consumption of energy in the building sector causes a considerable $\mathrm{CO}_{2}$ emission from buildings. The building sector accounts for $38 \%$, transport $34 \%$, industry $24 \%$ and agriculture $4 \%$ of the total $\mathrm{CO}_{2}$ emission in Iran.

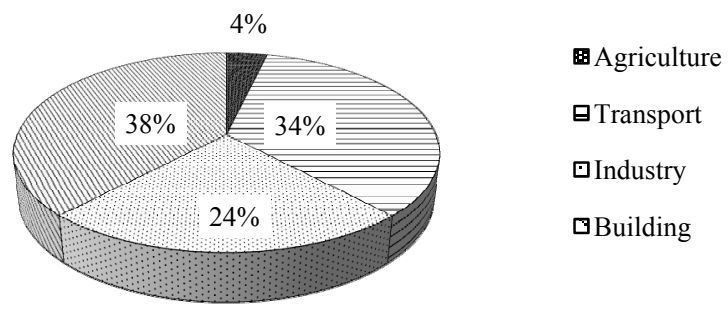

Figure 5: Share of $\mathrm{CO}_{2}$ emission resources in Iran in 2008 [5].

This paper investigates the Iranian buildings potential for greenhouse gas mitigation through the following aspects;

- Energy conservation policy in buildings

- Replacement of fossil fuel with renewable energy

\section{The energy conservation policy for the Iranian building sector}

\subsection{General energy efficiency policy}

In the Iranian second five-year plan (1995-1999), energy conservation issues have been considered. Following the assessment of initial projects during that 
period, further schemes and new ideas were developed in the third and fourth five-year plans. Here are some examples of these:

- Preparing technical specifications and standards for equipment.

- Imposing tariffs for importers and manufacturers who do not follow the consumption patterns related to energy efficiency standards.

- Allocating an appropriate fund for research into energy efficiency (equivalent to two percent of the total interest of energy sales).

- Preparing energy efficiency regulations in the design and construction of buildings in order to avoid energy waste.

- Setting up policies to encourage the use of efficiency standards in existing buildings.

- Incorporating energy efficiency schemes in education.

- Promoting energy efficient equipment and technologies for factories.

- Developing the principles of sustainable development in various regions.

\subsection{National energy efficiency regulation; Code No. 19}

The first national building code on energy conservation, Code No. 19, was approved in 1991 by the Ministry of Housing and Urbanism. It was revised several times and in 2001 finalised and imposed on construction and building organisations.

Code No.19 considers buildings energy conservation in different part of buildings, include [6]:

- External wall insulation

- Install double glazing windows with thermal brick frames, wooden or standard PVC

- Insulation of air channels, pipe installations and hot water production system

- Installation of local control systems such as thermostatic valves on the radiators

- Installation of weather compensators.

Currently Code No. 19 is mandatory for all public buildings. For other buildings a schedule has been introduced to apply improvements. Table 1; demonstrates the categorisation of provinces according to the climate they are located in. The priority in the schedule is for buildings with high demand of energy, for example cold and hot regions.

Table 1: $\quad$ Current Iranian counties categorised on energy demand [7].

\begin{tabular}{ccl}
\hline Category & $\begin{array}{c}\text { Energy } \\
\text { demand }\end{array}$ & \multicolumn{1}{c}{ Province } \\
\hline A & High & $\begin{array}{l}\text { Hormozgan, Bushehr, East Azerbaijan, West Azerbaijan, Chahar } \\
\text { mahaal and bakhtiari, Ardabil, Hamedan, Khoozestan and zanjan }\end{array}$ \\
\hline B & Medium & $\begin{array}{l}\text { Isfahan, Semnan, Kordestan, Qazvin, Kerman, Kermanshah, Markazi, } \\
\text { Fars, Ilam North Khorasan, South Khorasan, Razavi Khorasan, }\end{array}$ \\
\hline C & Low & $\begin{array}{l}\text { Lorestan, Gilan, Qom, Golestan, Mazandaran, Sistan and Baluchistan, } \\
\text { Kohgiluyeh and Boyer-ahmad, Yazd }\end{array}$ \\
\hline
\end{tabular}


Although the implementation of Code No. 19 in a building results in 5\% increase in initial cost, in the long term it will reduce the total building costs. The capacity of heating and cooling systems will be reduced by $40 \%$, which leads to a reduction in building expenses in the future [7].

\subsection{Barriers to the implementation of Code No. 19}

Progress in the implementation of Code No.19 is disappointingly slow, and has been only achieved to a level of approximately $20 \%$ of the target by 2010 [8]. The barriers to the implementation of Code No.19 include:

- Low energy price in the country

- Lack of the special code for residential buildings (Code No. 19 is a general code for all buildings)

- unrealistic legislation which is not considering executive potential of the country

- The high cost of code No. 19 and energy efficiency standards implementation

- Lack of assessment system to evaluate energy wastage and $\mathrm{CO}_{2}$ emission (Energy Performance Certificate)

- Lack of controlling bodies for Code No. 19 in order to control new buildings step by step

- Lack of co-operation and liaison with relevant organisations (Engineering, municipalities, Ministry of Housing and Institute of Standards, IFCO and ...) in the implementation of Code No. 19

- Insufficiently trained engineers, supervisors and architects for Code No. 19

- Lack of skilled workers in the fields of Code No. 19 (insulation, installing double glazing windows, Thermostatic valves and ...)

\section{Renewable energy development policy}

Today the increased consumption of energy worldwide and consequently the risk of quick exhaustion of fossil resources has forced the countries to look for further alternative energy resources. The decreasing level of fossil fuels is not the only reason to look into renewable energy. The main reason to switch to cleaner energy production is global warming. Burning of fossil fuel is the main source of carbon dioxide emission. Countries like Iran, with abundant oil and gas reserves, should not rely on those resources. Instead an energy policy should be introduced to encourage the use of a variety of alternative resources. Iran is considered to be one of the richest countries in the world with regards to different energy resources. Although it holds significant non-renewable fossil fuel resources, like oil and gas, it also has a great potential in terms of the renewable energies, like wind and solar energy. In Iran, further to policies made by the Ministry of the Energy's Deputy Directorate for Energy, Iran Renewable Energy Organization (SUNA) has been looking into this area since 1995, in order to gain further knowledge and develop technology for the utilization of 
renewable energy resources. Measurement of potentials and execution of various projects, including solar, wind, geothermal and biogas energy can be other alternatives.

\subsection{Solar energy}

Iran, in spite of being very rich in conventional energies, has also great potential for a large-scale application of solar energy systems. The country consists of $60 \%$ desert with high solar energy potential. The annual average sun radiation is $20-30 \mathrm{MJ} / \mathrm{m}^{2}$ in a day. The sunshine hours during the four seasons are as following: 700 hours during spring, 1050 hours in the summer, 830 hours during autumn and 500 hours in the winter [9]. As mentioned before, approximately $22 \%$ of the total energy consumption in residential buildings accounts for preparing hot water in buildings. With solar heaters around $70 \%$ of total energy usage for hot water could be saved [10]. Accordingly, the total energy demand in the building sector could be reduced by $15 \%$. In order to encourage individuals and the private sectors to use solar water heaters and photovoltaic converting systems the Iranian government has provided incentive policies such as substantial subsidies.

As it can be seen in Figure 6, solar power capacity has been 21 MW in 1998, and this increased dramatically to about $110 \mathrm{MW}$ in the year 2001. In 2002 due to the replacement of old equipment with modern technology, it reduced. Subsequently numerous power stations underwent repair works and thus the progress slowed down in 2005 [11]. Due to the unsatisfactory progress in Iran, on the one hand, and rapid progress in countries such as China and Turkey on the other hand, the need for swift action, along with International co-operation, becomes inevitable.

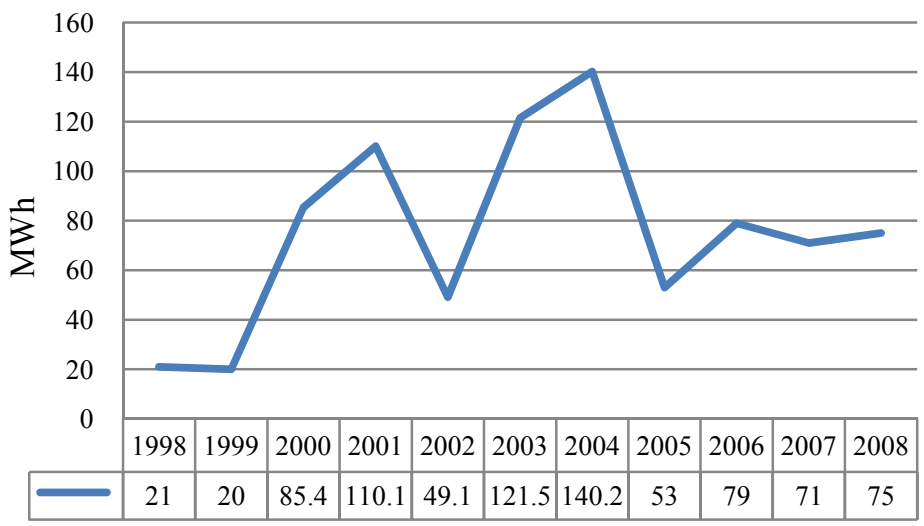

Figure 6: The solar power generation in Iran [11]. 


\subsection{Wind energy}

After the development of the environmental issues and critical concerns in the exploitation of non-renewable energy resources, the generation of wind energy is growing increasingly compared with other energy resources.

Iran is blessed with four completely distinctive seasons and has a number of vast deserts. The land of Iran is mostly mountainous; the Caspian Sea is located to the north and the Persian Gulf and Oman Sea are located in the southern part of the country. The geographical location of the country and its climate indicates the availability of areas with high wind energy potential. Furthermore, the country also experiences various tropical wind flows. These are the central flows from Central Asia during the winter and the Indian Ocean during the summer, the western flow from the Atlantic Ocean and the Mediterranean Sea during the winter, and the north western flow during the summer. Therefore, windelectricity generators could be a suitable substitute for non-renewable resources. Studies and evaluations regarding the wind potential in Iran demonstrate that in 26 regions (including more than 45 suitable areas) the nominal capacity of the sites is approximately $6500 \mathrm{MW}$, considering a general efficiency of 33\% [12].

Figure 7 illustrates the growth in the production of electricity with wind power in Iran between 2001 and 2008. The capacity of installed wind farms in Iran has shown an upward trend. In 2001 it was $10.8 \mathrm{MW}$, which increased dramatically to $89.9 \mathrm{MW}$ in the year 2008 .

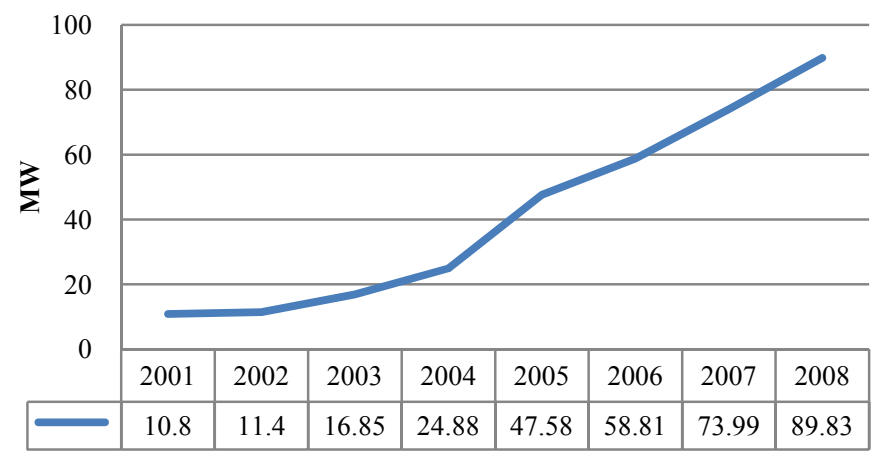

Figure 7: The capacity of installed wind farms in Iran [13].

The wind farms are mainly located at Gilan and Khorasan province. The Gilan wind farm capacity is $61.18 \mathrm{MW}$ at present; plans exist to enhance production up to $100 \mathrm{MW}$. Furthermore, the installation of another $60 \mathrm{MW}$ wind farm in the Qazvin province is currently being considered [13].

\subsection{Geothermal energy}

Interest in geothermal energy originated in Iran when James R. McNitt, a United Nations geothermal expert, visited the country in December 1974. In 1983 the 
result of several investigations identified the Sabalan, Damavand, Khoy-Maku and Sahand regions as four prospected geothermal sites in the northwest of Iran. Over the past decade SUNA has conducted a series of countrywide investigations in order to evaluate suitable zones for future investments. Ten potential geothermal sites were discovered in the country in addition to the four previously defined areas in the north-western part.

Sabalan was identified as the region with the highest potential in producing geothermal energy. Since 1995, surface exploration and feasibility studies have been carried out and five promising areas were discovered. Among those prospective areas around Sabalan region, the northwest part was selected for comprehensive sample testing to estimate the reservoir's characteristics and capacity [14]. At present, the main project in geothermal energy production is located near Meshkinshar in the Sabalan region, with a capacity of $50 \mathrm{MW}$ and the possibility of $370 \mathrm{MWh}$ annual energy productions [15].

\subsection{Biomass and biogas plants}

The main sources for biogas energy are domestic and industrial sewage, animal waste, and surplus of agricultural products as well as $80 \%$ of the country's domestic productions [9]. There are several benefits of using biogas, notably:

- Converting waste into two useful products

- Providing a smokeless fuel for cooking, lighting and generating electricity

- Transforming organic waste into high quality fertilizer (slurry)

- Keeping households and surroundings clean (waste management)

- Reducing fuel wood consumption and thus saving our forests

- Reducing environmental pollution and promotes family health

- Using human waste as a raw material for bio-latrines as bio-digesters.

Unlike fossil fuel combustion, biogas production from biomass is considered $\mathrm{CO}_{2}$ neutral and therefore does not emit additional Greenhouse Gases into the atmosphere. Hence, the focus is not only on the power production or its quantity, but on a healthy environment as the biomass energy resources are the best options. At present, two projects for this source of energy is considered in Mashhad and Shiraz with the capacity of 650 and $1060 \mathrm{KW}$ power respectively, from the solid waste of the two cities. The future target is to produce $10 \mathrm{MW}$ power from the waste of several large cities. A pilot prototype project for biogas is operating in Saveh, south west of Tehran, with a capacity of $600 \mathrm{KW}$ power [16].

\subsection{Barriers to the implementation of renewable energy in Iran}

Despite the advantages of the geographical location of Iran for the extensive use of renewable energy sources, only 38 percent of the government target in the implementation of renewable energy policies has been achieved [17]. To meet the government targets, more detailed planning and a meticulous schedule should be introduced. The barriers to the implementation of renewable energy policies have been reviewed below: 
- The lack of a comprehensive national plan with relevant detailed guidelines

- Incorrect timing of the release of funds

- Lack of skilled specialists, consultants and controlling bodies

- Ignorance of the need for development of renewable energies as a result of highly subsidised energy carriers

- Low public awareness of the importance of renewable energy and the role of public participation in the development of renewable energy.

\subsection{Conclusions and suggestions}

There is a great potential to reduce building energy consumption in Iran. In recent years the government has paid more attention to building energy conservation. National energy and environment policies in the government's national development plans, has resulted in the establishing of Renewable Energy Organization (SUNA) and Iranian Fuel Conservation Company (IFCO), have addressed the serious attempts of the government. Programmes focusing on energy efficiency and renewable energy sources have been introduced in order to reduce the negative impact of the enormous fossil fuel energy consumption. Furthermore, Code No. 19 has been compiled in 1991 in the building sector as a result of this strategy.

However, there is still a significant gap in energy efficiency between Iran and other developed countries. In 2010, Code No. 19 and renewable energy policies have been implemented by 20 and 38 percent, respectively. Accordingly, it is essential to establish more efficient strategies to meet the government targets. Possible solutions to overcome barriers in implementing such policies are as follows:

- Preparing a code for energy efficiency in residential building designs with detailed specification and guidelines (Code No. 19 is set for all buildings and is not just for residential buildings).

- Producing local energy efficiency policies considering the vast climate diversity in Iran.

- Setting incentive policies to enhance the interests of the private sector in energy conservation in buildings.

- Allocating appropriate funds to all areas of the countries; (big cities, small towns and rural areas).

- Introducing strict legislation and controlling bodies by local governments to enhance the implementation of regulations and policies in buildings at all stages.

- Replacing fossil fuels with renewable energy sources in building designs.

- Promoting environmentally compatible and highly energy-efficient building materials.

- Setting up a monitoring, evaluation and impact assessment system and producing the energy performance certificate which illustrates energy efficiency and $\mathrm{CO}_{2}$ emission rating in domestic properties. The EPC 
(Energy Performance Certificate) will increase the occupant's awareness of environmental impact of buildings.

- Training and educating professionals in the sector in order to raise their environmental consciousness.

- Educating building occupants and the public to raise their environmental consciousness and responsibility towards the environment.

- Improving the international co-operation in order to exchange experiences and to share knowledge of advanced technologies with the country.

\section{Abbreviations}

1. Iranian fuel conservation company (IFCO)

2. Iran Renewable Energy Organization (SUNA)

\section{References}

[1] Energy planning office, Energy Balance 2008, Ministry of Energy: Tehran, pp. 303, 2010.

[2] Iranian Fuel Conservation Company (IFCO), Buildings office website, 2010 http://ifco.ir/building/amozesh/catalog/guide.pdf, pp3.

[3] Energy planning office, Energy Balance 2008, Ministry of Energy: Tehran, pp. 42, 2010.

[4] Iranian Fuel Conservation Company (IFCO), Buildings office website, 2010 http://ifco.ir/building/amozesh/catalog/solar_final.pdf, pp10.

[5] Energy planning office, Energy Balance 2008, Ministry of Energy: Tehran, pp. $269,2010$.

[6] Iranian Fuel Conservation Company (IFCO), Buildings office website, 2010 http://www.ifco.ir/english/building/energy/title19.asp\#

[7] Energy planning office, Energy Balance 2008, Ministry of Energy: Tehran, pp. 308, 2010.

[8] Kazemi, Government notification website, April 2010 http://www.dolat.ir/NSite/FullStory/?id=188530

[9] Ghorashi, A.H. \& Rahimi, A. Rahimi, Renewable and non-renewable energy status in Iran: Art of know-how and technology-gaps, Renewable and Sustainable Energy Reviews, Volume 15, PP. 729-736, 2010

[10] Iranian Fuel Conservation Company (IFCO), Buildings office website, 2010 http://ifco.ir/building/amozesh/catalog/solar final.pdf, pp9.

[11] Energy planning office, Energy Balance 2008, Ministry of Energy: Tehran, pp. 241, 2010.

[12] Renewable Energy Organization of Iran (SUNA), February 2011 http://www.suna.org.ir/executive-windandwaves-windoffice-en.html

[13] Energy planning office, Energy Balance 2008, Ministry of Energy: Tehran, pp. 236-237, 2010. 
[14] Noorollahi, Y., Yousefi, H., Itoi, R. \& Ehara, S., Geothermal energy resources and development in Iran, Renewable and Sustainable Energy Reviews, Volume 13, PP. 1127-1132, 2009

[15] Energy planning office, Energy Balance 2008, Ministry of Energy: Tehran, pp. 243, 2010.

[16] Energy planning office, Energy Balance 2008, Ministry of Energy: Tehran, pp. 245, 2010.

[17] Fadai, D., Esfandabadi, Z. Sh. \& Abbasi, A., A Review on the Causes of Failure in Achieving the Goals of Iran's Renewable Energy Sector in the Fourth Development Plan, Iranian journal of Energy, Volume 34, PP. 2334,2010 